\title{
POLOIDAL FLUX LINKAGE REQUIREMENTS FOR THE INTERNATIONAL THERMONUCLEAR EXPERIMENTAL REACTOR
}

\author{
S.C. JARDIN, C.E. KESSEL, N. POMPHREY \\ Princeton Plasma Physics Laboratory, \\ Princeton University, \\ Princeton, New Jersey, \\ United States of America
}

\begin{abstract}
Two computational models have been applied to calculate the poloidal flux linkage requirements for the current ramp-up and for the flat-top phase of the proposed International Thermonuclear Experimental Reactor (ITER). For the current ramp-up phase, the TSC code has been used to simulate the entire current ramp-up period as described in the TAC-3 Report. The time of the simulation has been extended to cover the full current penetration time, that is, until the loop voltage is a constant throughout the plasma. Sensitivity studies have been performed with respect to current ramp-up time, impurity concentration and to the time of onset of auxiliary heating. A steady state plasma equilibrium code has been used that has the constant loop voltage constraint built in to survey the dependence of the steady state loop voltage on the density and temperature profiles. This calculation takes into account the plasma bootstrap current contribution, including non-circular and collisional corrections. The results can be displayed as contours of the loop voltage on a POPCON-like diagram.
\end{abstract}

\section{INTRODUCTION}

The International Thermonuclear Experimental Reactor (ITER), now into its engineering design phase, is to be the largest, most ambitious, controlled fusion experiment ever built [1]. It represents a significant step along the path towards developing a commercial fusion reactor. The total plasma current and the linear dimensions in ITER are each approximately 3 times larger than the largest fusion experiments preceding it, and are of the approximate size that will be needed in a demonstration fusion electrical power plant.

The importance of ITER and the large leap in parameters represented by it necessitate that we use all available established analysis techniques to predict and to optimize the plasma performance. It is in this spirit that we have applied TSC [2] and JSOLVER [3] to calculate the flux linkage requirements during the current ramp-up and steady state in ITER. The Tokamak Simulation Code (TSC), in particular, has been calibrated against the plasma current ramp-up phase of many experimental discharges in TFTR [4] and other tokamaks. It has been used extensively as a design tool in PBX-M, CIT, BPX, C-MOD, TCV, ASDEX Upgrade, HIB-II and other tokamaks.

In the next section we describe the TSC model of ITER which was used in these studies. We then describe a TSC simulation of the plasma current ramp-up in ITER. This represents an independent calculation of the startup phase described in the ITER TAC-3 report. The subsequent sections describe the results found with TSC regarding the plasma ramp-up time, and the amount of flux linkage change that the poloidal field coil system must supply both during the current ramp-up and the steady state. We finally summarize the primary conclusions of this study.

\section{THE TSC MODEL}

The TSC [2] is a two dimensional (2-D) time dependent free boundary simulation code that advances the MHD equations describing the transport time-scale evolution of an axisymmetric magnetized tokamak plasma. TSC evolves the magnetic field in a rectangular computational domain using the Maxwell MHD equations for the plasma, coupled through boundary conditions to the circuit equations for the tokamak poloidal field (PF) coils. The plasma model in TSC is completed by providing functional forms for the electron and ion thermal conductivities, for the particle diffusion coefficients, and for the plasma electrical resistivity. Thus, TSC evolves 2-D variables for the magnetic poloidal and toroidal fluxes, but utilizes flux co-ordinate mappings to solve 1-D equations for the surface averaged temperatures and densities.

The details of the TSC model are presented in Ref. [4] where the results of TSC are compared in detail with the results from seven ohmic discharges in TFTR. We note here that the model includes the following features:

(a) Separate energy equations for electrons and for ions,

(b) Neoclassical resistivity,

(c) Bootstrap current, 
(d) A time averaged sawtooth model,

(e) The Coppi-Tang transport model,

(f) Radiation from fully stripped ions only.

In the present studies, the plasma density is not evolved in time but is given by the prescribed function

$n_{\mathrm{e}}(\psi, t)=n_{0}(t)\left[(1-\psi)^{N_{1}}+n_{\mathrm{b}}\right]$ where $\psi$ is the normalized poloidal flux that is zero at the magnetic axis and unity at the boundary, and $n_{0}(t)$ is input to be a piecewise linear function of time. In this study we took $N_{1}=0.5$ and $n_{\mathrm{b}}=0.3$ to represent a broad density profile with a peak-to-average ratio equal to 1.4 .
TABLE I. COIL CENTRES AND WIDTHS

\begin{tabular}{ccccc}
\hline Coil & $R_{\mathrm{c}}(\mathrm{m})$ & $Z_{\mathrm{c}}(\mathrm{m})$ & $\Delta R(\mathrm{~m})$ & $\Delta Z(\mathrm{~m})$ \\
\hline $\mathrm{la}$ & 2.29 & 0.00 & 0.339 & 12.00 \\
$\mathrm{lb}$ & 2.67 & 0.00 & 0.413 & 12.00 \\
2 & 5.95 & 9.98 & 0.865 & 0.865 \\
3 & 13.01 & 7.20 & 0.585 & 1.170 \\
4 & 15.19 & -2.45 & 0.805 & 1.170 \\
5 & 15.19 & -5.75 & 0.805 & 1.170 \\
6 & 9.65 & -9.64 & 1.080 & 1.170 \\
7 & 5.18 & -9.49 & 1.080 & 1.170 \\
8 & 2.02 & 1.30 & 0.188 & 5.000 \\
\hline
\end{tabular}

TABLE II. TSC PFC FEEDBACK SYSTEM RATIOS

\begin{tabular}{cccr}
\hline $\begin{array}{c}\text { Coil } \\
\text { number }\end{array}$ & $\begin{array}{c}\text { Radial } \\
\text { feedback }\end{array}$ & $\begin{array}{c}\text { Vertical } \\
\text { feedback }\end{array}$ & $\begin{array}{c}\text { Plasma } \\
\text { current (A) }\end{array}$ \\
\hline $1 \mathrm{a}$ & - & - & 51984 \\
$1 \mathrm{~b}$ & - & - & 76092 \\
2 & - & - & 19630 \\
3 & 1.00 & 1.00 & 750 \\
4 & 0.56 & 1.89 & 1230 \\
5 & 0.56 & -4.03 & -1020 \\
6 & - & - & 2640 \\
7 & - & - & 19390 \\
\hline
\end{tabular}

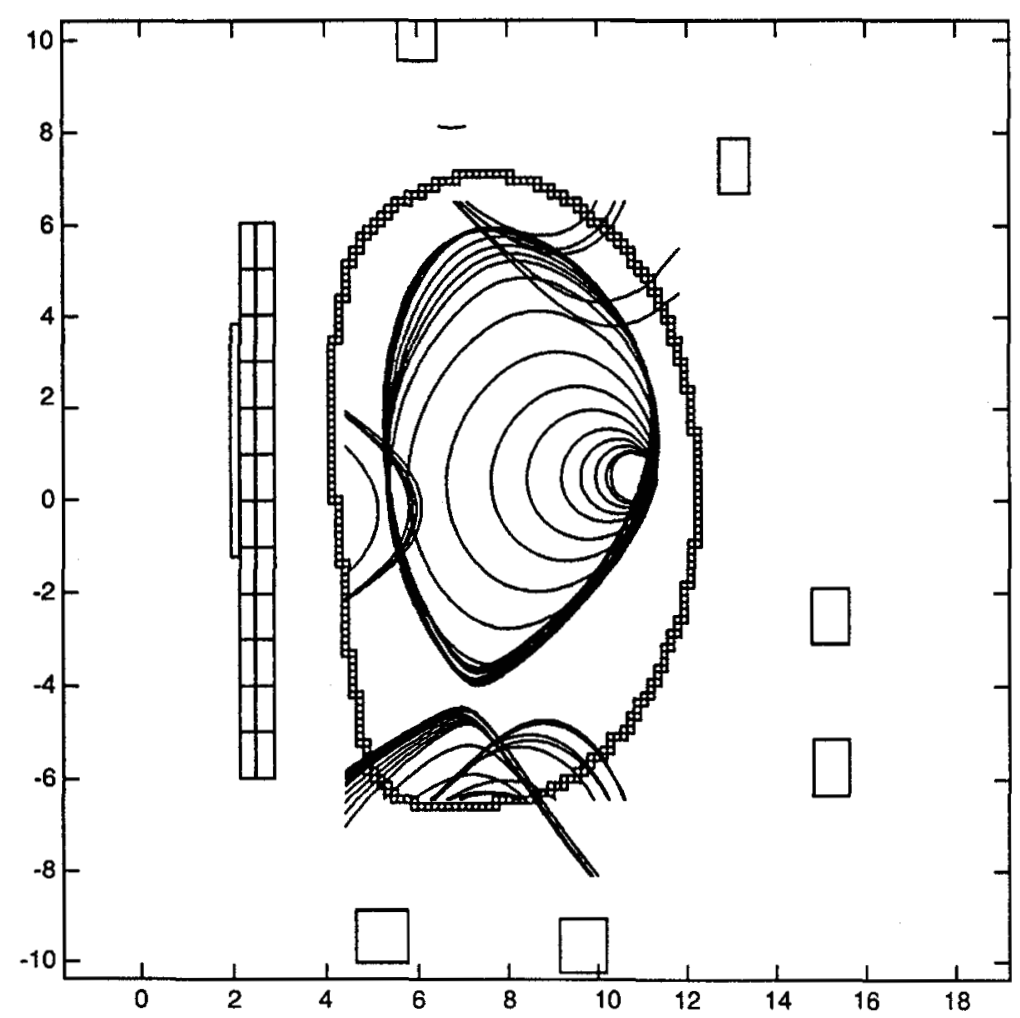

FIG. 1. Poloidal field coil cross-sections, vacuum vessel and plasma-vacuum interface at selected times in TSC simulation of ITER startup. 

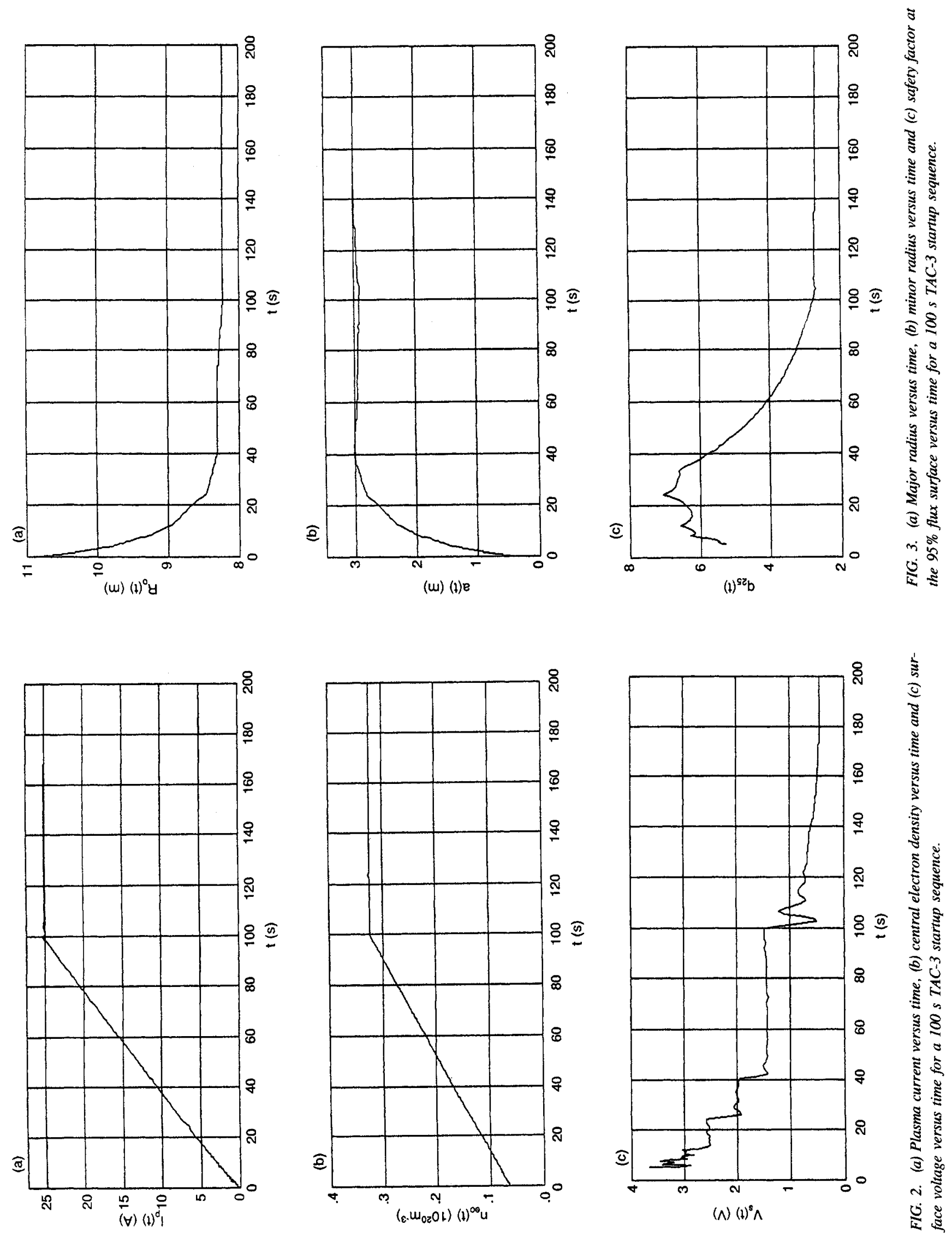

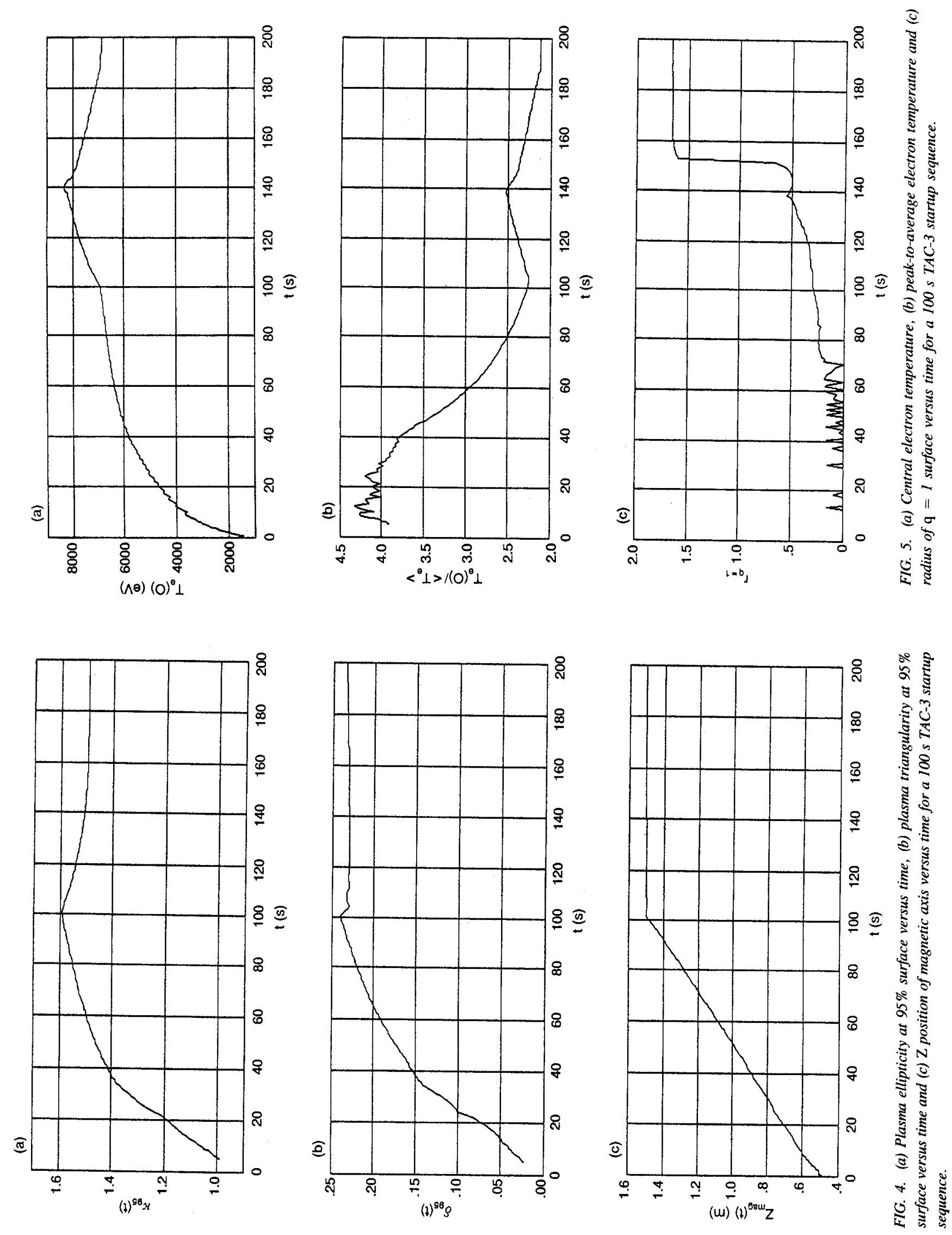


\section{SIMULATION OF THE TAC-3 STARTUP}

We have used TSC to model the startup sequence described in the TAC-3 report [5]. The toroidal field was held constant at a value of $R B_{\mathrm{T}}=48.35 \mathrm{~T} \cdot \mathrm{m}$. The $\mathrm{PF}$ coil locations and dimensions are described in Table $I$. The current in each coil is the sum of the preprogrammed current and the current in up to three feedback systems which control the radial position, the vertical position and the total plasma current. The coils involved in the three feedback systems and the turns ratios for each of these systems are shown in Table II. There were no additional feedback systems for plasma shape control used in this calculation. A vacuum vessel is included in the calculation with a total toroidal resistance of $27 \mu \Omega$.

\subsection{Plasma parameters versus time}

The initial condition for the simulation was taken to be a $100 \mathrm{kA}$ plasma with major and minor radius $R=$ $10.77 \mathrm{~m}$ and $a=0.46 \mathrm{~m}$, with $Z_{\mathrm{mag}}=0.5 \mathrm{~m}$, and in contact with a limiter point at $R_{\mathrm{lim}}=11.20 \mathrm{~m}, Z_{\mathrm{lim}}=0.20 \mathrm{~m}$.
The plasma current was subsequently increased linearly in time to a maximum value of $25 \mathrm{MA}$ at $t=100 \mathrm{~s}$, and was then kept at this constant value for the remainder of the simulation time of $200 \mathrm{~s}$. The plasma-vacuum interface at snapshot intervals during this time is shown in Fig. 1, as are the poloidal field coils and the TSC representation of the vacuum vessel. The plasma remained limited until $t=40 \mathrm{~s}$ (at $I_{\mathrm{p}}=10 \mathrm{MA}$ ), when a separatrix surface became limiting with the single $X$ point being in the lower part of the chamber. The plasma parameters as a function of time are shown in Figs 2 to 5.

The plasma density was a prescribed function of time as indicated in Eq. (1) and Fig. 2(b). The surface voltage trace in Fig. 2(c) was the loop voltage at the plasma boundary produced by the changing coil currents in TSC in order to cause the plasma current to have the time trajectory shown in Fig. 2(a).

The plasma major radius $R$ and magnetic axis $Z$ position $Z_{\text {mag }}$ were programmed to be functions of time as shown in Figs 3(a) and 4(c), respectively. The corresponding trajectory for the minor radius $a(t)$ is shown in Fig. 3(b). The programming of $R(t)$ was chosen to

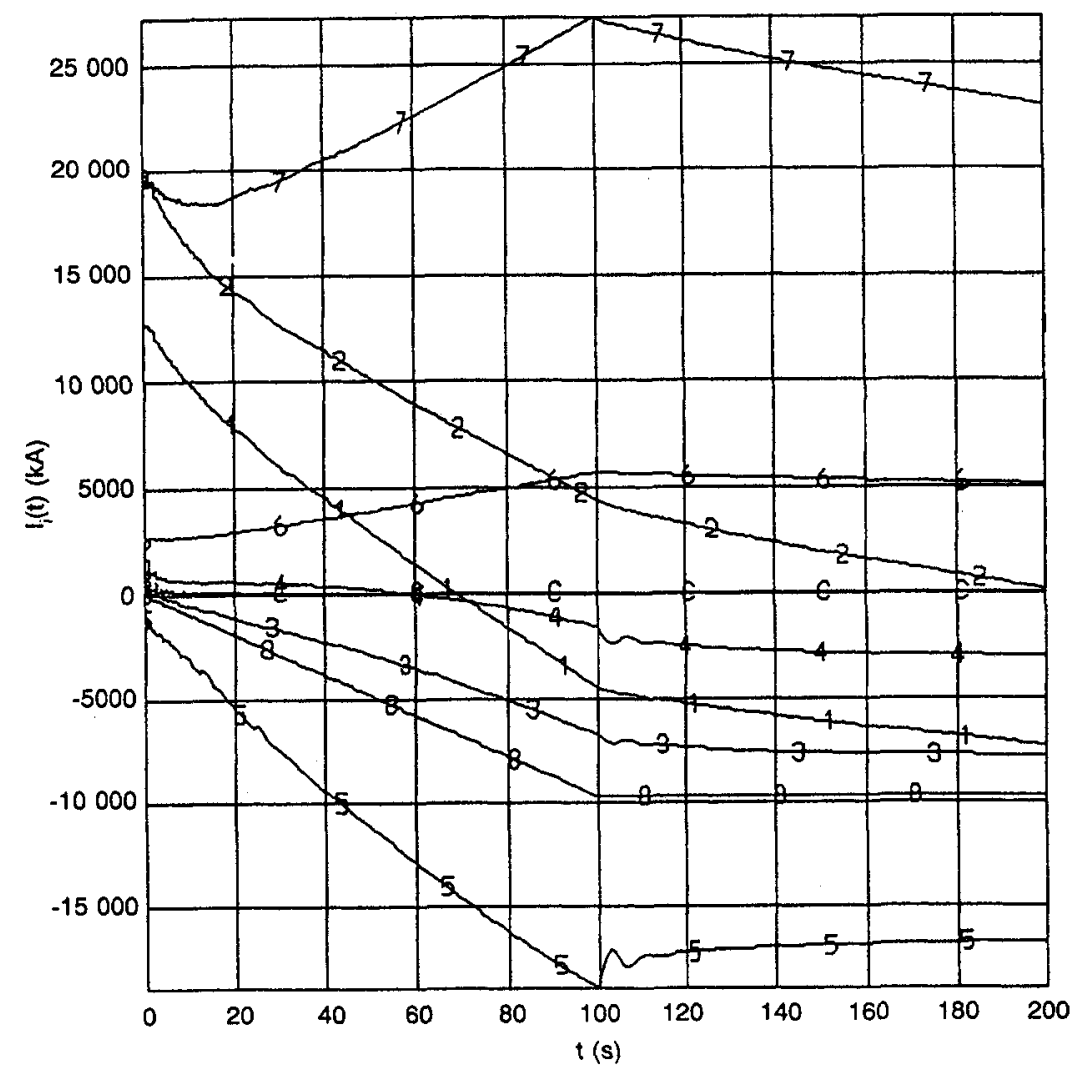

FIG. 6. Poloidal field coil currents versus time for a TAC-3 startup sequence. Note that the current for case 1 has been divided by 10 so as not to distort the scale. 
TABLE III. PREPROGRAMMED AND ACTUAL CURRENTS (MA'turns)

\begin{tabular}{crrrrrrr}
\hline & \multicolumn{3}{c}{ Preprogrammed } & & \multicolumn{3}{c}{ Actual } \\
Coil & \multicolumn{1}{c}{$I(0)$} & $I(100)$ & $I(200)$ & & $I(0)$ & $I(100)$ & $I(200)$ \\
\hline $1 \mathrm{a}$ & 52.00 & -31.88 & -31.88 & 52.00 & -18.44 & -29.58 \\
$1 \mathrm{~b}$ & 76.08 & -46.64 & -46.64 & 76.08 & -26.98 & -43.28 \\
2 & 19.63 & -0.70 & -0.70 & 19.63 & 4.37 & 0.17 \\
3 & 0.75 & -7.71 & -7.71 & 0.73 & -6.80 & -7.75 \\
4 & 1.23 & -3.08 & -3.08 & 1.26 & -1.80 & -3.03 \\
5 & -1.02 & -16.42 & -16.42 & -1.17 & -18.21 & -16.65 \\
6 & 2.64 & 5.02 & 5.02 & 2.64 & 5.70 & 5.13 \\
7 & 19.39 & 22.18 & 22.18 & 19.39 & 27.19 & 23.03 \\
8 & 0.00 & -9.71 & -9.71 & 0.00 & -9.71 & -9.71 \\
\hline
\end{tabular}

TABLE IV, STANDARD TAC-3 STARTUP

\begin{tabular}{ccccc}
\hline Parameter & & $t=0$ & $t=100 \mathrm{~s}$ & $t=200 \mathrm{~s}$ \\
\hline$I_{\mathrm{p}}(\mathrm{MA})$ & $\mathrm{I}^{\mathrm{a}}$ & 0.1 & 25 & 25 \\
$\left\langle n_{\mathrm{e}}\right\rangle\left(\mathrm{m}^{-3}\right)$ & $\mathrm{I}$ & $0.05 \times 10^{20}$ & $0.23 \times 10^{20}$ & $0.23 \times 10^{20}$ \\
$Z_{\text {eff }}$ & $\mathrm{I}$ & 1.1 & 1.1 & 1.1 \\
$R_{0}(\mathrm{~m})$ & $\mathrm{I}$ & 10.76 & 8.21 & 8.21 \\
$a(\mathrm{~m})$ & $\mathrm{I}$ & 0.5 & 3.0 & 3.0 \\
$Z_{\text {mag }}(\mathrm{m})$ & $\mathrm{I}$ & 0.5 & 1.5 & 1.5 \\
$P_{\text {rad }}(\mathrm{MW})$ & $\mathrm{C}$ & 0.0 & 1.60 & 1.68 \\
$P_{\text {OH }}(\mathrm{MW})$ & $\mathrm{C}$ & 0.2 & 11.8 & 11.0 \\
$l_{\mathrm{i}}(1)$ & $\mathrm{C}$ & 1.2 & 0.93 & 1.15 \\
$l_{\mathrm{i}}(3)$ & $\mathrm{C}$ & 1.2 & 0.79 & 1.00 \\
$r(q=1)(\mathrm{m})$ & $\mathrm{C}$ & - & 0.25 & 1.66 \\
$I_{\mathrm{bs}}(\mathrm{MA})$ & $\mathrm{C}$ & 0.0 & 0.346 & 0.32 \\
$T_{\mathrm{e}}(0)(\mathrm{keV})$ & $\mathrm{C}$ & 1.3 & 6.9 & 7.0 \\
$T_{\mathrm{e}}(0) /\left\langle T_{\mathrm{e}}\right\rangle$ & $\mathrm{C}$ & 3.5 & 2.3 & 2.1 \\
$\tau_{\mathrm{e}}(\mathrm{s})$ & $\mathrm{C}$ & 0.25 & 9.5 & 9.5 \\
$\beta(\%)$ & $\mathrm{C}$ & 0.006 & 0.19 & 0.20 \\
$\Delta \Phi_{\mathrm{R}}(\mathrm{axial})(\mathrm{Wb})$ & $\mathrm{C}$ & - & 18 & 49 \\
$\Delta \Phi_{\mathrm{I}}(\mathrm{axial})(\mathrm{Wb})$ & $\mathrm{C}$ & - & 170 & 198 \\
$\Delta \Phi_{\mathrm{R}}($ Poynting $)(\mathrm{Wb}) \mathrm{C}$ & - & 86 & 117 \\
$\Delta \Phi_{\mathrm{I}}($ Poynting $)(\mathrm{Wb}) \mathrm{C}$ & - & 102 & 130 \\
$C_{\mathrm{E}}$ & $\mathrm{C}$ & - & 0.34 & 0.45 \\
$\Delta \Phi_{\text {total }}(\mathrm{Wb})$ & $\mathrm{C}$ & - & 430 & 490.9 \\
\hline & & & & \\
\hline
\end{tabular}

a Input to the simulation.

${ }^{b}$ Calculated by TSC. produce a $95 \%$ safety factor $q_{95}$ which is initially in the range of $6-7$, and decreases monotonically in time as shown in Fig. 3(c). The traces shown in Figs 3 and 4 are outputs from the TSC simulation where the control of $R(t)$ and $Z_{\text {mag }}(t)$ was realized by a feedback system using the currents in the PF coils 3-5 in the ratios indicated in Table II. The plasma ellipticity and triangularity, $\kappa_{95}(t)$ and $\delta_{95}(t)$, shown in Figs 4(a) and (b), respectively, are also the results of the TSC simulation. There were no special feedback systems to control these shape parameters, although this is an option for a future simulation.

The central and peak-to-average electron temperatures calculated as a function of time are shown in Figs 5(a) and (b), and the computed minor radius of the $q=1$ surface is shown in Fig. 5(c). (Note the apparent discontinuity at $t=150 \mathrm{~s}$ indicating the existence of a non-monotonic $q$ profile prior to this time.) Figure 6 shows the time trajectories of each of the eight coil currents as used in the TSC simulation. Note that the curve labelled ' 1 ' in Fig. 6 is the sum of the currents in coils $1 \mathrm{~A}$ and $1 \mathrm{~B}$, divided by 10 so as not to distort the plot scale. Both the preprogrammed and actual coil currents at times $t=0,100$ and $200 \mathrm{~s}$ are also listed in Table III for reference. Table IV lists selected plasma parameters at these same times. The second column in that table indicates whether the given quantity was an input to the simulation (I) or calculated by TSC (C). 


\subsection{Flux linkage requirements}

A quantity of interest for machine design is the total poloidal flux swing needed at a certain location in the plasma chamber to build up and sustain the plasma current for the entire discharge. This flux swing is produced by changing currents in all eight PF coils, constrained at all times by the requirement that the field they produce is the one needed at that instant for plasma equilibrium and shaping. We choose the point of reference to be at $R_{\text {ref }}=$ $8.20 \mathrm{~m}, Z_{\text {ref }}=0.0 \mathrm{~m}$. We call the total poloidal flux change at this reference point $\Delta \Phi_{\text {total }}$. TSC calculates this directly by using Green's functions and the computed coil currents to keep track of how much the flux due to the PF coils changes at $\left(R_{\text {ref }}, Z_{\text {ref }}\right)$.

The poloidal flux change can be divided into two natural pieces: an 'external' piece corresponding to the flux produced by the plasma current through a toroidal strip between the machine axis $(R=0)$ and the inside edge of the plasma, $R=R_{0}-a$, and an 'internal' piece corresponding to the sum of the flux produced by the plasma current through a strip between $R_{0}-a$ and $R_{\text {ref }}$ and the flux consumed in the plasma by the resistive dissipation. Thus

$\Delta \Phi_{\text {total }}=\Delta \Phi^{\text {external }}+\Delta \Phi^{\text {internal }}$

The external flux change $\Delta \Phi^{\text {external }}$ is calculated in TSC by using Eq. (2), and subtracting the change in flux at the plasma vacuum interface, $\Delta \Phi^{\text {internal }}$, from $\Delta \Phi_{\text {total }}$. The plasma internal flux, $\Delta \Phi^{\text {internal }}$, is also normally divided into two pieces for accounting purposes: an 'inductive' component due to the magnetic field within the plasma, and a 'resistive' component that accounts for the resistive consumption. There are two commonly used methods that approach this division from different points of view. While each is internally consistent and both yield the same sum when applied correctly, the two methods can give quite different results for the inductive and resistive parts

The axial method is based on flux conservation and thus has a simple physical picture associated with it [6]. In the axial method, the plasma internal flux is divided into two parts, the inductive component, $\Delta \Phi_{\mathrm{I}}$ (axial), and the resistive component, $\Delta \Phi_{\mathrm{R}}$ (axial). These are defined as the flux difference between the plasma boundary and the plasma axis, and the flux change at the magnetic axis, respectively.

The Poynting scheme [7] is based on energy conservation. Since it deals with quantities that are more readily measured experimentally, it is the one that is most widely used. The TSC code keeps track of both methods but, since the ITER results are now normally quoted in terms of the Poynting method, we will emphasize that approach here. Thus, in the Poynting method we have

$\Delta \Phi^{\text {internal }}=\Delta \Phi_{\mathrm{I}}($ Poynting $)+\Delta \Phi_{\mathrm{R}}($ Poynting $)$

The inductive part of the internal flux is calculated using the internal inductance $l_{\mathrm{i}}$ [sometimes called $l_{\mathrm{i}}(3)$ ] according to

$\Delta \Phi_{\mathrm{I}}($ Poynting $)=\mu_{0} R_{0} I_{\mathrm{p}} \frac{l_{\mathrm{i}}}{2}$

where

$\frac{l_{\mathrm{i}}}{2}=\frac{\int B_{\mathrm{p}}^{2} \mathrm{~d} V}{R_{0} \mu_{0}^{2} I_{\mathrm{p}}^{2}}$

In TSC, the resistive part of the internal flux in the Poynting method is then calculated from Eqs (2) to (5) by $\Delta \Phi_{\mathrm{R}}($ Poynting $)=\Delta \Phi_{\text {total }}-\Delta \Phi^{\text {external }}-\Delta \Phi_{\mathrm{I}}$ (Poynting)

It is also common to introduce an 'Ejima coefficient', $C_{\mathrm{E}}$, by the relation

$\Delta \Phi_{\mathrm{R}}($ Poynting $)=C_{\mathrm{E}} \mu_{0} R_{0} I_{\mathrm{p}}$

In TSC, Eqs (2) to (7) are used to calculate $C_{\mathrm{E}}$ in terms of the change in flux at the plasma vacuum interface, $\Delta \Phi^{\text {internal }}$, the plasma major radius $R_{0}$, the plasma current $I_{\mathrm{p}}$ and the internal inductance $l_{\mathrm{i}}$ as follows:

$C_{\mathrm{E}}=\frac{\Delta \Phi^{\text {internal }}}{\mu_{0} R_{0} I_{\mathrm{p}}}-\frac{l_{\mathrm{i}}}{2}$

It is clear from Eq. (8) that the Ejima coefficient $C_{\mathrm{E}}$ is a function of time for a given discharge. Its value is normally quoted at the end of the current ramp, although we will see that this may not be the most meaningful time. We also note here that the Ejima coefficient, as defined, will depend on the choice of the reference point $\left(R_{\text {ref }}\right.$, $\left.Z_{\text {ref }}\right)$. This is just a matter of our bookkeeping conventions regarding how the total flux is divided into external inductive, internal inductive and internal resistive components. We follow the normal convention here in defining $R_{\text {ref }}$ to be the geometrical centre of the final configuration and $Z_{\text {ref }}$ to be zero.

The different measures of the flux swing requirements as computed in the standard TAC-3 startup sequence are given in Table IV both at the end of the current ramp, $t=100 \mathrm{~s}$, and at a time which is after the end of the current equilibration period, $t=200 \mathrm{~s}$. Recall that the meaningful number for engineering design is the bottom line in Table IV, $\Delta \Phi_{\text {total }}$. 


\section{THE PLASMA CURRENT RAMP-UP TIME}

One of the important decisions that the ITER designers must make is to specify the plasma current ramp-up time. The primary physics trade-offs are that faster current ramp-ups lead not only to less resistive flux consumption at the end of the ramp-up time, but also to increased probability of disruption as the plasma passes through equilibrium states where the plasma current is peaked offaxis. There are, of course, also engineering trade-offs in that faster current ramp-ups imply larger power supplies and increased eddy current heating of the structures. These will not be considered here except to note that they favour lower current ramp rates.

To study the physics trade-off issues, we have performed the series of TSC runs shown in Table $V$. Case 2 in Table V is the TAC-3 startup simulation discussed in Section 3. Cases 1, 3 and 4 are identical except that the plasma current (and density) risetimes were changed from $100 \mathrm{~s}$ to $40 \mathrm{~s}, 120 \mathrm{~s}$ and $160 \mathrm{~s}$, respectively. The results of these four runs are compared in Figs 7 to 16.

Figure 7 shows the flux difference between the magnetic axis and the plasma boundary as a function of time for the four cases. In our notation, this is $\Delta \Phi_{\mathrm{I}}$ (axial). What is noteworthy is how much longer than the ramp-up time it takes for this quantity to reach its steady state value, especially for the fast $40 \mathrm{~s}$ ramp-up, case 1 . Even though the plasma current was increased to its maximum value of $25 \mathrm{MA}$ at $t=40 \mathrm{~s}$, we see that $\Delta \Phi_{1}$ (axial) is only $66 \%$ of its steady state value at that time. It takes another $120 \mathrm{~s}$ for $\Delta \Phi_{\mathrm{I}}$ (axial) to reach $99 \%$ of its steady state value. In contrast, we see that, for the $160 \mathrm{~s}$ ramp, case $4, \Delta \Phi_{1}$ (axial) has already achieved almost $95 \%$ of its maximum at the end of the ramp. It takes only another $30 \mathrm{~s}$ to reach $99 \%$ of its final value. For this latter case, the current penetration time is much better matched to the current ramp-up time.

This same phenomena is illustrated in another way in Fig. 8 where we plot $l_{1} / 2$ versus time for the same four cases. We note the common feature in these curves that $l_{\mathrm{i}}$ decreases during the current ramp to a minimum value at the end of the ramp that we call $l_{i}^{\min }$. It then increases to its steady state value of $l_{\mathrm{i}}^{\mathrm{ss}}=1.00$. We define $t_{\text {crit }}$ as the time when $l_{\mathrm{i}}$ has come to within $1 \%$ of its final value of $l_{\mathrm{i}}^{\text {ss }}$. If $l_{\mathrm{i}}^{\min }=l_{\mathrm{i}}^{\text {ss }}$, then $t_{\text {crit }}=t_{\text {ramp }}$. Both $t_{\text {crit }}$ and $l_{\mathrm{i}}^{\min }$ for the four cases are listed in Table V and plotted in Fig. 9.

We see from Figs 8 and 9 and from Table $\mathrm{V}$ that $l_{i}^{\min }$ is a strong function of $t_{\text {ramp }}$ in this parameter regime. The real question is: What value of $l_{i}^{\min }$ is acceptable in that it will not lead to increased plasma disruptivity? Approximate guidance can be obtained by looking at the trajectories of the discharges in $l_{\mathrm{i}} / 2$ versus $q_{\mathrm{cyln}}$ space and comparing them with the cylindrical limit theoretical results of Ref. [8]. This has been done for three of these discharges as shown in Fig. 10.

\section{TABLE V. PARAMETER SCAN OF FLUX-SWING REQUIREMENTS DURING RAMP-UP}

(Three sets of cases, totaling 11 cases in all, were run to determine the parametric effects of current ramp-up time, $\mathrm{t}_{\text {ramp}}$, and the effective charge state, $\mathrm{Z}_{\text {eff, }}$ and the effect of auxiliary heating during the current ramp. Lines shown in bold indicate the cases that have the minimum stable current ramp time for that group of parameters. $\mathrm{t}_{\text {crit }}$ is the time when the plasma current reached a steady state for that simulation case. Auxiliary heating applied at $\mathrm{t}=0.7 \mathrm{t}_{\text {ramp. }}$.)

\begin{tabular}{|c|c|c|c|c|c|c|c|c|c|}
\hline Case & $\begin{array}{l}t_{\text {ramp }} \\
(\mathrm{s})\end{array}$ & $Z_{\text {eff }}$ & $\begin{array}{l}\text { Aux. heat } \\
\text { (MW) }\end{array}$ & $l_{\mathrm{j}}^{\min }$ & $\begin{array}{l}t_{\text {crit }} \\
(\mathrm{s})\end{array}$ & $\begin{array}{c}\Delta \Phi(200) \\
(\mathrm{Wb})\end{array}$ & $C_{\mathrm{E}}(200)$ & $\begin{array}{c}\Delta \Phi\left(t_{\text {crit }}\right) \\
(\mathrm{Wb})\end{array}$ & $C_{\mathrm{E}}\left(t_{\text {crit }}\right)$ \\
\hline 1 & 40 & 1.1 & 0 & 0.54 & 160 & 487 & 0.44 & 467 & 0.37 \\
\hline 2 & 100 & 1.1 & 0 & 0.78 & 160 & 491 & 0.45 & 471 & 0.39 \\
\hline 3 & 120 & 1.1 & 0 & 0.84 & 170 & 491 & 0.45 & 476 & 0.41 \\
\hline 4 & 160 & 1.1 & 0 & 0.90 & 195 & 491 & 0.45 & 489 & 0.45 \\
\hline 5 & 40 & 2.5 & 0 & 0.63 & 115 & 520 & 0.56 & 467 & 0.36 \\
\hline 6 & 100 & 2.5 & 0 & 0.86 & 130 & 522 & 0.57 & 479 & 0.42 \\
\hline 7 & 120 & 2.5 & 0 & 0.90 & 145 & 522 & 0.57 & 488 & 0.45 \\
\hline 8 & 160 & 2.5 & 0 & 0.94 & 185 & 522 & 0.57 & 513 & 0.53 \\
\hline 9 & 100 & 1.1 & 10 & 0.75 & 190 & 470 & 0.37 & 468 & 0.36 \\
\hline 10 & 160 & 1.1 & 10 & 0.85 & 220 & 470 & 0.39 & 477 & 0.41 \\
\hline 11 & 200 & 1.1 & 10 & 0.90 & 250 & 470 & 0.43 & 488 & 0.45 \\
\hline
\end{tabular}




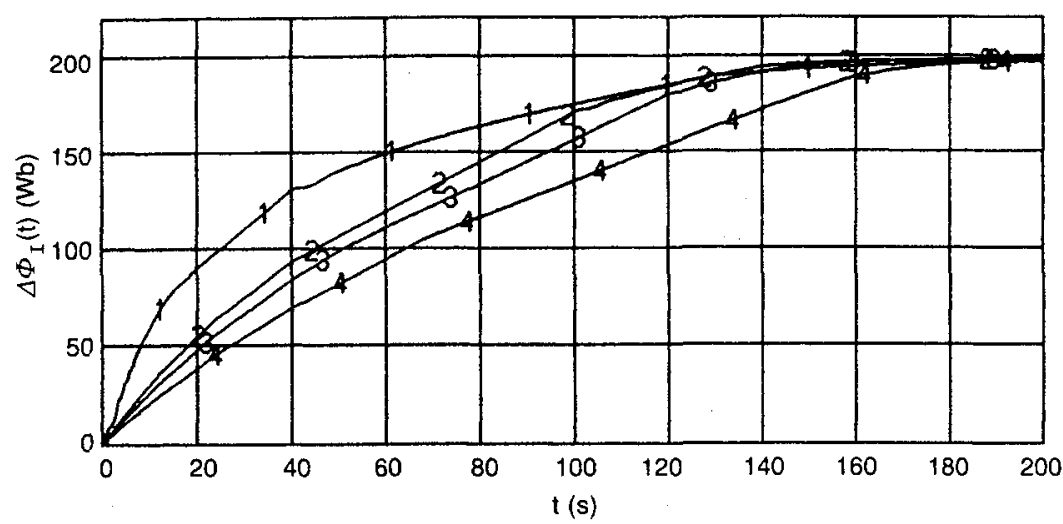

FIG. 7. Inductive part of internal flux versus time using the axial accounting method. Case 1 has a current ramp-up time $\mathrm{t}_{\text {ramp }}=40 \mathrm{~s}$, case 2 has $\mathrm{t}_{\text {ramp }}=100 \mathrm{~s}$, case 3 has $\mathrm{t}_{\text {ramp }}$ $=120 \mathrm{~s}$ and case 4 has $\mathrm{t}_{\text {ramp }}=160 \mathrm{~s}$.

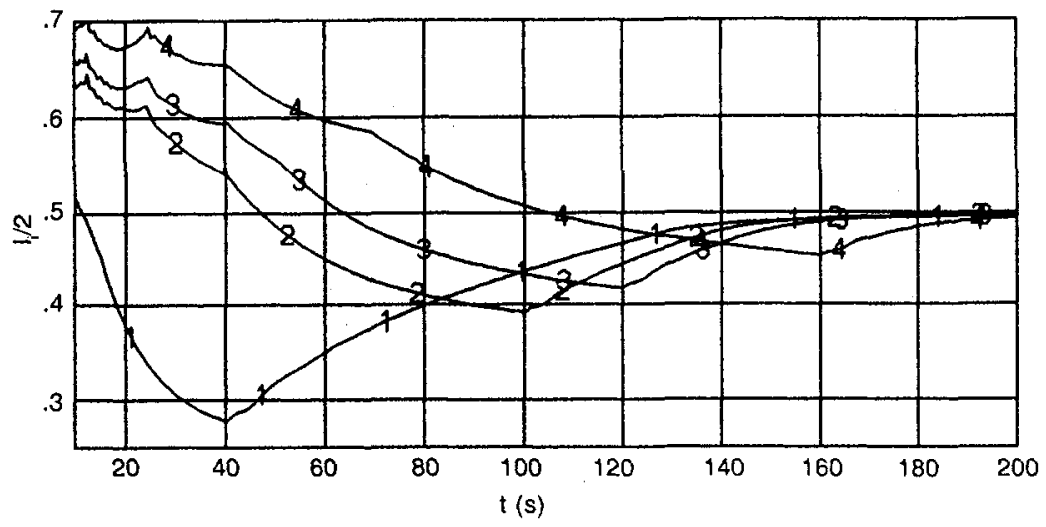

FIG. 8. Internal inductance $1_{i} / 2$ versus time. Case 1 has a current ramp-up time $\mathrm{t}_{\text {ramp }}$ $=40 \mathrm{~s}$, case 2 has $\mathrm{t}_{\text {ramp }}=100 \mathrm{~s}$, case 3 has $\mathrm{t}_{\text {ramp }}=120 \mathrm{~s}$ and case 4 has $\mathrm{t}_{\text {ramp }}=160 \mathrm{~s}$.

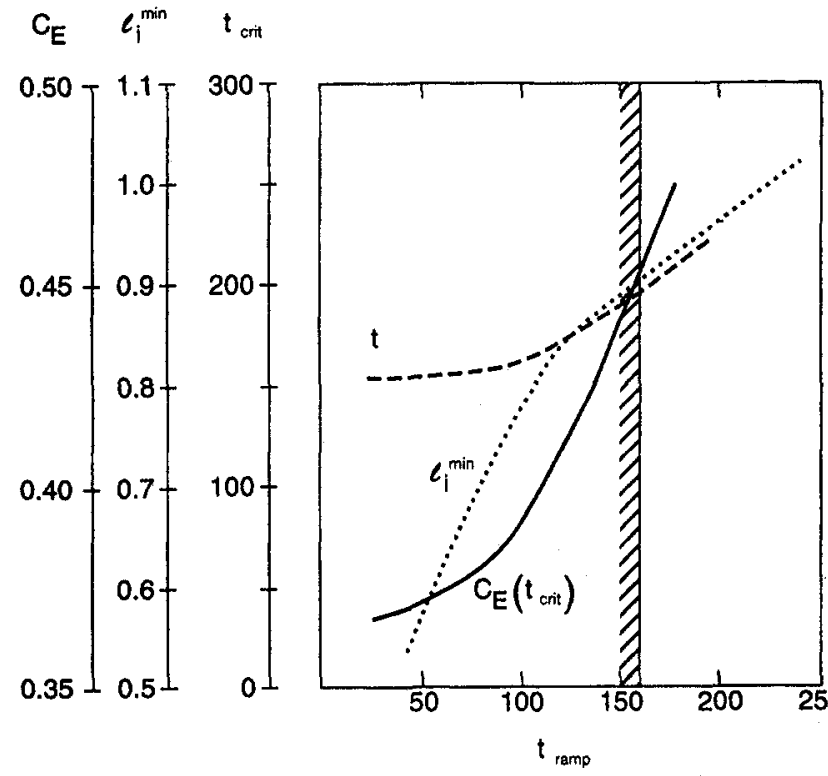

FIG. 9. The minimum value of the internal inductance, $1_{i}^{\min }$, the time for the discharge to equilibrate to its steady state profiles, $\mathrm{t}_{c r i t}$, and the Ejima coefficient, $\mathrm{C}_{E}$, evaluated at $\mathrm{t}_{\text {crit }}$ as functions of current ramp-up time $\mathrm{t}_{\text {ramp }}$ for the TAC-3 parameters with $\mathrm{Z}_{\text {eff }}=1.1$.
From the three current ramp trajectories plotted in Fig. 10, we see that cases 1 and 2 with current ramp-up times of $t_{\text {ramp }}=40$ and $100 \mathrm{~s}$ are unsatisfactory according to this criteria since they cross into the shaded region corresponding to kink-mode instability. Case 4, corresponding to a current ramp-up time of $t_{\text {ramp }}=160 \mathrm{~s}$, looks to be just marginally acceptable. This is largely confirmed by Fig. 11 which shows midplane current profiles for these three cases as time progresses throughout the current ramp-up period. It is seen that the discharges with $t_{\text {ramp }}=40$ and $100 \mathrm{~s}$ develop off-axis current peaks, while the 160 s current ramp-up discharge does not. Note that the central flattening of these current profiles is due to the sawtooth model in TSC, which tends to make the parallel resistivity inside the $q=1$ surface uniform.

Thus, we take the minimum value of $l_{i}$ which occurs for case $4, l_{i}^{\min }=0.90$, as being the smallest acceptable value. Faster current ramp-up times which lead to values of $l_{i}^{\min }$ less than 0.90 are considered here to be unphysical. 

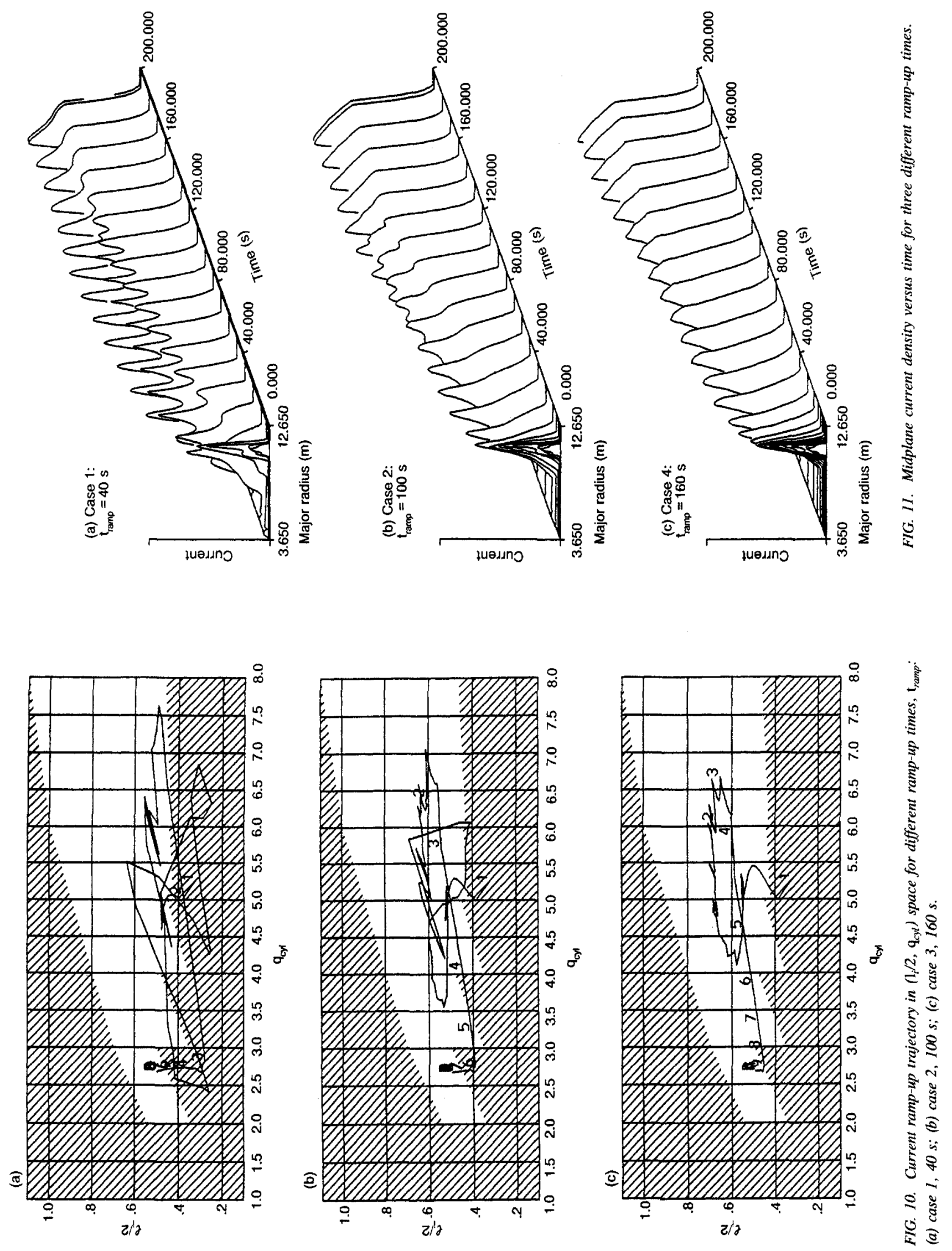

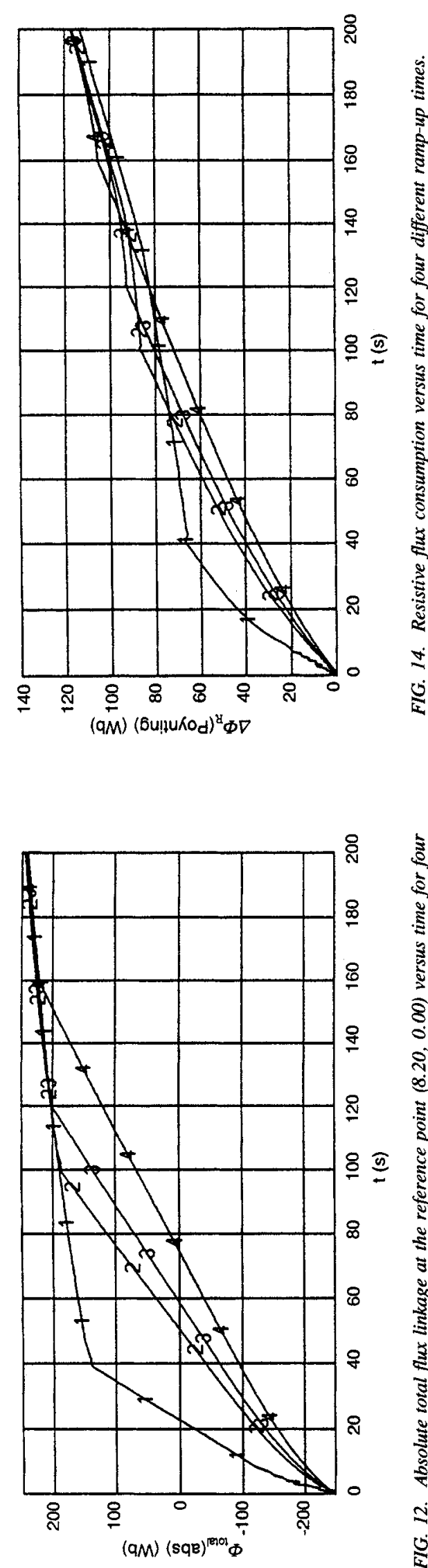

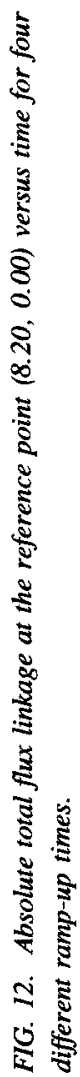
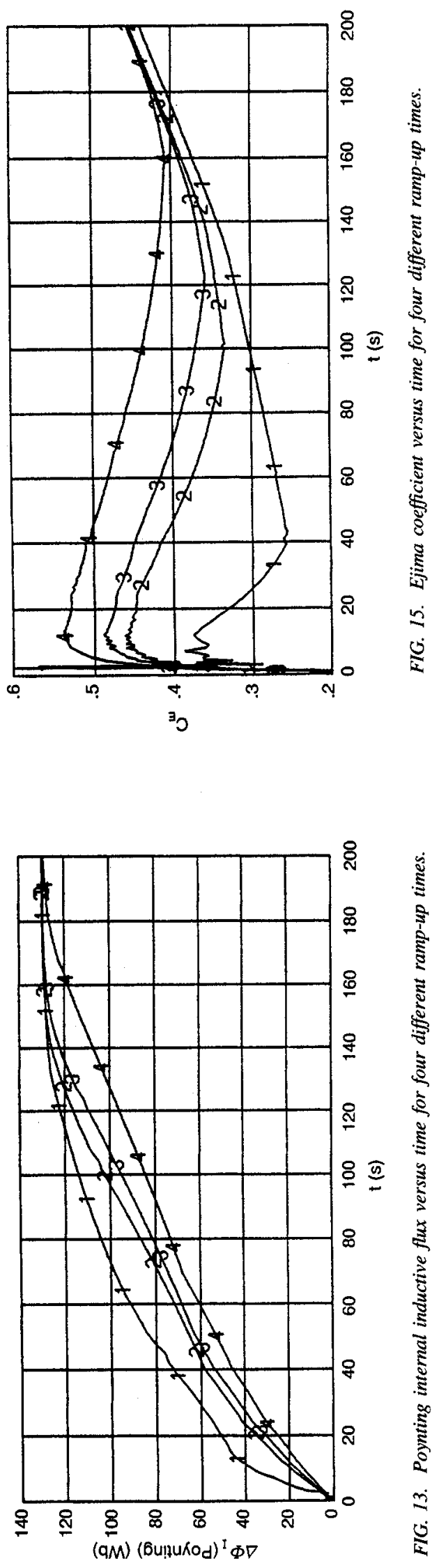


\section{FLUX CONSUMPTION DURING PLASMA CURRENT RAMP-UP}

Figure 12 shows plots of the absolute value of the poloidal flux produced by the PF coil currents at the reference point $(8.20,0.0)$ as a function of time for the four cases 1 to 4 . We see that while the flux change from time zero until the end of each of the respective current ramp-up times, $\Delta \Phi_{\text {total }}\left(t_{\text {ramp }}\right)$, increases with $t_{\text {ramp }}$, the value of the flux change from time zero to the fixed time $t=200 \mathrm{~s}, \Delta \Phi_{\text {total }}(200)$, is independent of $t_{\text {ramp }}$ to within $1 \%$ for current ramp-up times in the range $40<t_{\text {ramp }}$ $<160 \mathrm{~s}$. This interesting result implies that, for a purely ohmically heated plasma, the change in total flux linkage needed to get to a given time in the stationary phase of the discharge is independent of the details of the current ramp-up, and depends only on the time since the beginning of the current ramp and on the total plasma current.

We plot in Figs 13,14 and 15 the quantities $\Delta \Phi_{1}$ (Poynting), $\Delta \Phi_{\mathrm{R}}$ (Poynting) and $C_{\mathrm{E}}$, respectively, versus time for the four cases. A key quantity of interest to the ITER designers is the amount of flux consumed from the time of plasma current initiation until the end of the plasma current penetration phase. This quantity is clearly minimized by making $t_{\text {ramp }}$ as small as possible, subject to stability constraints. The previous discussion implies that these stability constraints limit ITER plasma current ramp-up times to those in excess of $t_{\text {ramp }}>160 \mathrm{~s}$ for the plasma density and plasma purity parameters of Table IV.

However, we see from Figs 7 to 15 that, even at the end of a $150 \mathrm{~s}$ current ramp-up, the current profile is still not in a resistive stationary state. This can also be seen from Fig. 16 which shows midplane profiles of the surface loop voltage at different times for case 4 with $t_{\text {ramp }}$ $=160 \mathrm{~s}$. In a stationary state, the loop voltage becomes constant across flux surfaces as it does at later times in
Fig. 16. Other indications that the plasma profiles are not steady state at the end of the plasma current ramp are that the plasma internal inductive flux linkage $\Delta \Phi_{\mathrm{I}}$ (axial), Fig. 7 , and $\Delta \Phi_{\mathrm{I}}$ (Poynting), Fig. 13, and the plasma internal inductance, $l_{i}$, Fig. 8 , are still changing in time.

The fact that these different quantities are still changing indicates that the plasma current has not fully penetrated into the plasma at the end of the current ramp. It would be misleading to quote the flux swing requirements at $t=t_{\text {ramp }}$. Later in the discharge the current equilibration will still occur and the additional increase in flux linkage necessitated by it will not be properly accounted for by assuming that the time rate of change of flux linkage needed for times $t>t_{\text {ramp }}$ is given totally by the surface loop voltage. This point has also been noted in experimental studies on Tore Supra [9].

What is more meaningful is to quote the flux swing requirements from the beginning of the current ramp to the time when the current has relaxed to its steady state value. We have defined this time above as $t_{\text {crit }}$, which is the time when $l_{i}$ increases to within $1 \%$ of its steady state value of 1.00 . For case 4 with the $160 \mathrm{~s}$ current ramp which satisfies the stability requirement of $l_{i}^{\min } \geq 0.90$, we see from Table V and Figs 8 and 9 that $t_{\text {crit }}=195 \mathrm{~s}$. From Figs 12 and 15, we see that the total flux swing and the corresponding Ejima coefficient at this time are $\Delta \Phi_{\text {total }}=490$ and $C_{\mathrm{E}}=0.45$, respectively. These are the values that should be quoted for the total poloidal flux consumption during plasma current ramp-up for the TAC-3 parameters.

\subsection{Effects of $Z_{\text {eff }}$}

In the cases 1-4 discussed so far, the assumed impurity concentration was very low so that the effective charge for the neoclassical resistivity calculation was $Z_{\text {eff }}=1.1$.

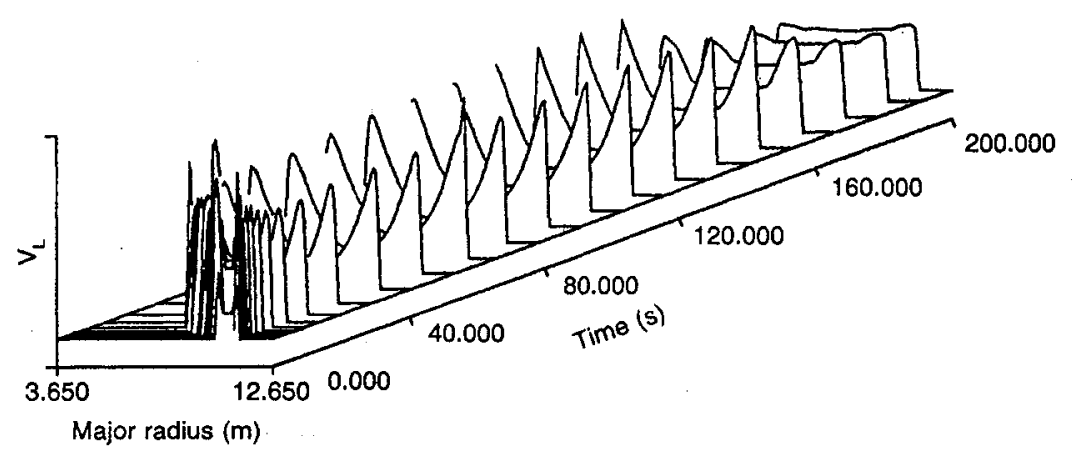

FIG. 16. Midplane loop voltage $\mathrm{V}_{L}$ versus time for case 4 with $\mathrm{t}_{\text {ramp }}=160$ s. Maximum voltage scale is $1.45 \mathrm{~V}$ and final constant value is $0.45 \mathrm{~V}$. 
If $Z_{\text {eff }}$ is larger than this, there will be several partially offsetting factors that affect the flux consumption calculation. Larger $Z_{\text {eff }}$ will cause the plasma resistivity to be larger, which will increase the resistive flux consumption evaluated at a given time in the discharge. However, this is largely offset by two effects. The first is due to the $T_{\mathrm{e}}^{-3 / 2}$ dependence of the plasma resistivity. Since the ohmic heating is also greater with larger $Z_{\text {eff }}$, the plasma temperature at a given time in the current ramp will also be greater, partially offsetting the increase of the plasma resistivity due to the larger $Z_{\text {eff }}$. More importantly, any increase in the resistivity that does occur will make the plasma resistive time shorter. This allows ramping the plasma current up faster without violating the stability constraint. This will again be offsetting since the quantity of interest is the required total flux swing between $t=0$ and $t=t_{\text {crit }}$, and this effect will allow $t_{\text {crit }}$ to be shorter.

To quantify this, we have repeated the calculations summarized in Fig. 9, but have changed $Z_{\text {eff }}$ from 1.1 to 2.5. The corresponding results are presented both in Table $\mathrm{V}$ as cases 5, 6, 7 and 8 and in Fig. 17. With $Z_{\text {eff }}$ increased from 1.1 to 2.5 , the minimum stable ramp-up time has decreased from 160 to $120 \mathrm{~s}$. The corresponding $t_{\text {crit }}$ has decreased from 195 to $145 \mathrm{~s}$, at which time the Ejima coefficient is $C_{\mathrm{E}}=0.45$. Thus, the outcome is essentially unchanged from the result with $Z_{\text {eff }}=1.1$.

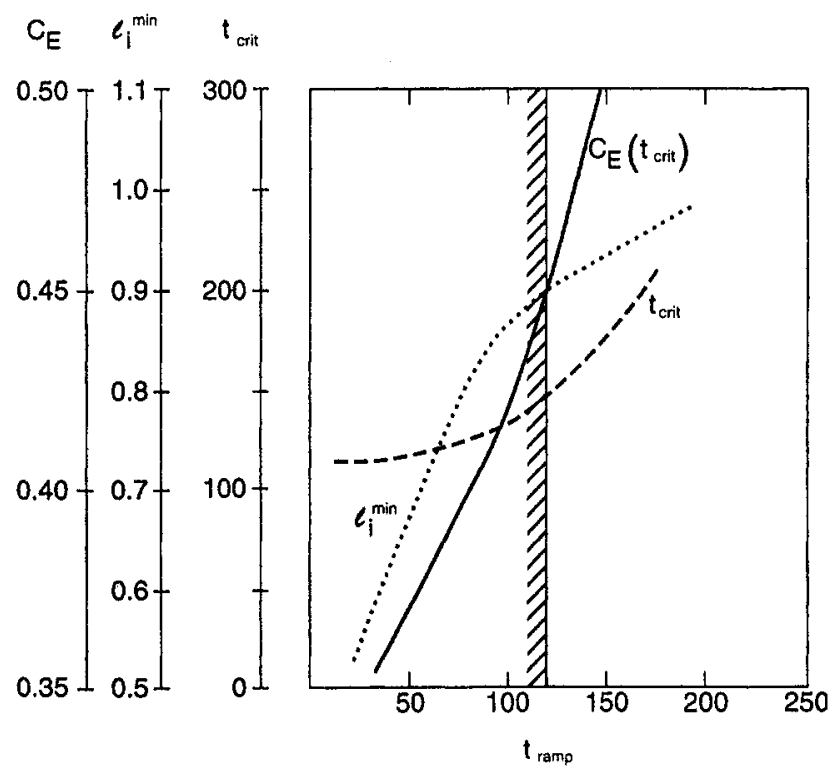

FIG. 17. The minimum value of the internal inductance, $1_{i}^{\text {min }}$, the time for the discharge to equilibrate to its steady state profiles, $\mathrm{t}_{c r i t}$, and the Ejima coefficient, $\mathrm{C}_{E}$, evaluated at $\mathrm{t}_{c r i t}$ as functions of current ramp-up time $\mathrm{t}_{\text {ramp }}$ for the $T A C-3$ parameters with $\mathrm{Z}_{\text {eff }}=2.5$ (for comparison with Fig. 9).
For both cases, the total required flux swing from the transformer evaluated at $t=t_{\text {crit }}, \Delta \Phi_{\text {total }}\left(t_{\text {crit }}\right)$, is in the range $488-489 \mathrm{~Wb}$.

The conclusion of this section is that the primary result of increasing $Z_{\text {eff }}$ is to increase the current penetration time so that the plasma current can be ramped up faster without loss of MHD stability. If the plasma current is indeed ramped up faster as allowed, then the flux swing requirements to get to the stationary phase of the discharge will be the same as for the lower $Z_{\text {eff }}$ case.

\subsection{Supplementary heating during the current ramp}

A similar but opposite effect is seen when we look at the effect of supplementary heating during current ramp-up and compare it with the baseline current ramp-up sequences of Fig. 9. We refer to the simulations denoted cases 9,10 and 11 in Table $\mathrm{V}$, and summarized in Fig. 18. In these runs, we went back to the baseline parameters $\left(Z_{\text {eff }}=1.1\right)$, but added $10 \mathrm{MW}$ of centrally peaked auxiliary heating, beginning when the plasma current reached $70 \%$ of its final value, and continuing throughout the remainder of the discharge. We see that the effect of the auxiliary heating is to increase the current penetration time so that the minimum current ramp-up

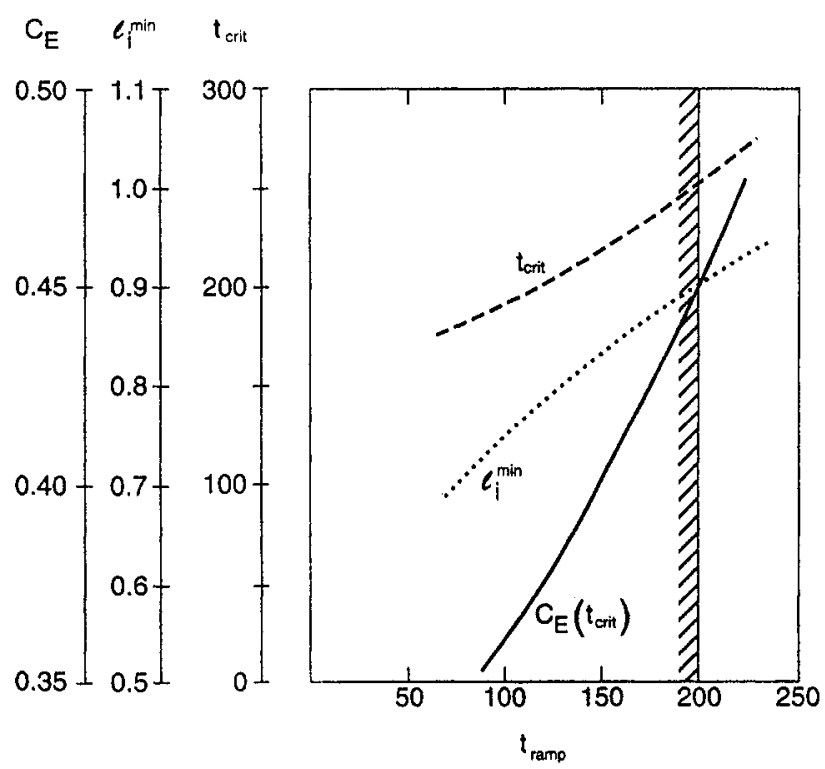

FIG. 18. The minimum value of the internal inductance, $1_{i}^{m i n}$, the time for the discharge to equilibrate to its steady state profiles, $\mathrm{t}_{c r i}$, and the Ejima coefficient, $\mathrm{C}_{E}$, evaluated at $\mathrm{t}_{\text {crit }}$ as functions of current ramp-up time $\mathrm{t}_{\text {ramp }}$ for the TAC-3 parameters with $\mathrm{Z}_{\text {eff }}=1.1$ and with $10 \mathrm{MW}$ auxiliary heating applied when $\mathrm{I}_{p}=17.5 \mathrm{MA}$. 
time increases to $200 \mathrm{~s}$ and the corresponding critical time $t_{\text {crit }}$ increases from 195 to $250 \mathrm{~s}$.

Thus, even though the heated plasma has a higher temperature and thus a lower resistivity, the longer rampup time and the corresponding increase in $t_{\text {crit }}$ cause the requirement on the flux swing needed to get to the stationary phase of the discharge to remain unchanged. Again, it is characterized by an Ejima coefficient of $C_{\mathrm{E}}=0.45$.

\section{FLUX CONSUMPTION DURING A STEADY BURN}

In steady state, the plasma loop voltage is constant across the plasma cross-section and is completely determined by the plasma density and temperature profiles, the total plasma current $I_{\mathrm{p}}$, the effective charge $Z_{\text {eff }}$ and the shape of the outer plasma boundary. This loop voltage $V_{L}$ is the time rate of change of resistive flux consumption that needs to be supplied by the changing flux linkage from the currents in the poloidal field coils.

Since this stationary equilibrium state is completely specified by the above parameters, we can calculate this directly with an equilibrium solver, without having to use

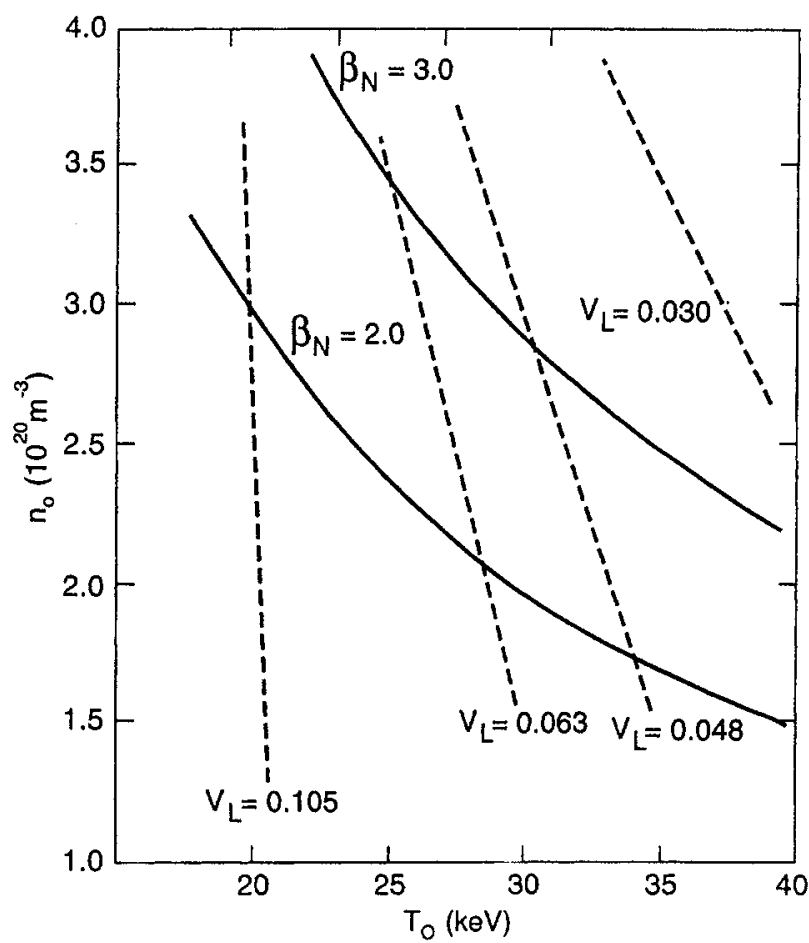

FIG. 19. Contours of loop voltage $\mathrm{V}_{L}$ in $\left(\mathrm{n}_{0}, \mathrm{~T}_{0}\right)$ space for $\mathrm{I}_{p}=$ $25 M A, \mathrm{Z}_{\text {eff }}=1.1$ and density and temperature profiles given by Eqs (9) and (10), respectively.
TSC to go through the time dependent portion of the discharge. This has been done using the new JSOLVER program [3], using density and temperature profiles of the forms

$n(\psi)=n_{0}\left(1-\psi^{b_{n}}\right)^{a_{n}}$

and

$T(\psi)=T_{0}\left(1-\psi^{b_{T}}\right)^{a_{T}}$

JSOLVER then calculates the corresponding stationary equilibrium solution which is consistent with the parallel Ohm's law, subject to the constant loop voltage constraint. We use the Hirshman single ion formula [10] for the bootstrap current in general geometry, extended to include collisional corrections [11]. Thus, the form of the current profile used in the Grad-Shafranov equilibrium calculation is determined from the constraint of being stationary,

$V_{\mathrm{L}}=2 \pi \eta\left(\frac{\langle J \cdot B\rangle}{\langle B \cdot \nabla \phi\rangle}-\frac{\langle J \cdot B\rangle_{\mathrm{bs}}}{\langle B \cdot \nabla \phi\rangle}\right)$

Here the loop voltage $V_{\mathrm{L}}$ is a constant, $\eta$ is the neoclassical resistivity [4], $\phi$ is the symmetry angle in the toroidal direction, and the bootstrap current is defined by

$$
\begin{aligned}
& \frac{\langle J \cdot B\rangle_{\text {bs }}}{\langle B \cdot \nabla \phi\rangle}=-\frac{p_{\mathrm{e}}}{\left\langle 1 / R^{2}\right\rangle} \\
& \quad \times\left\{A_{1}^{\mathrm{H}}\left[\frac{1}{p_{\mathrm{e}}} \frac{\mathrm{d} p_{\mathrm{e}}}{\mathrm{d} \psi}+\frac{p_{\mathrm{i}}}{p_{\mathrm{e}}}\left(\frac{1}{p_{\mathrm{i}}} \frac{\mathrm{d} p_{\mathrm{i}}}{\mathrm{d} \psi}-\alpha_{\mathrm{i}}^{\mathrm{H}} \frac{1}{T_{\mathrm{i}}} \frac{\mathrm{d} T_{\mathrm{i}}}{\mathrm{d} \psi}\right)\right]\right. \\
& \left.\quad-\left(\frac{5}{2} A_{1}^{H}-A_{2}^{H}\right)\left(\frac{1}{T_{\mathrm{e}}} \frac{\mathrm{d} T_{\mathrm{e}}}{\mathrm{d} \psi}\right)\right\}
\end{aligned}
$$

The superscripts $H$ here refer to coefficients that extend the original values defined in Ref. [9] to those approximating collisional corrections as described in Ref. [10].

In finding these equilibria, we keep the total plasma current $I_{\mathrm{p}}$ and $Z_{\text {eff }}$ fixed, and solve for the loop voltage $V_{L}$. The results are then plotted in Fig. 19 as contours of $V_{\mathrm{L}}$ in the space defined by $n_{0}$ and $T_{0}$. To generate that figure we have defined the coefficients in Eqs (9) and (10) as $b_{n}=10, a_{n}=0.5, b_{T}=1.25$ and $a_{T}=1.0$. This leads to profiles with $n_{0} /\langle n\rangle=1.1$ and $T_{0} /\langle T\rangle=2.3$. In addition, we have $I_{\mathrm{p}}=25 \mathrm{MA}, R B_{\mathrm{T}}=48.35 \mathrm{~T} \cdot \mathrm{m}$, $Z_{\text {eff }}=1.4, R_{0}=8.2, a=3.0, \kappa=1.5$ and $\delta=0.23$.

\section{SUMMARY AND RECOMMENDATIONS FOR FURTHER WORK}

We have applied the time dependent TSC and stationary JSOLVER codes to calculate the flux linkage require- 
ments for a tokamak with the proposed parameters of ITER. We find that the plasma current penetration time limits the current ramp-up rate to about $160 \mathrm{~s}$, corresponding to a rate of $0.156 \mathrm{MA} / \mathrm{s}$ for the standard TAC-3 startup parameters (including $Z_{\text {eff }}=1.1$ ). For these plasma parameters, faster current ramps will lead to plasma current profiles during the transient that are unstable according to the approximate MHD criteria used here.

If $Z_{\text {eff }}$ is increased, the plasma current diffusion time will decrease and this will allow the plasma current to be ramped up faster and still remain MHD stable. If the ramp-up time is indeed increased as permitted by MHD stability, the amount of total flux linkage change required to reach the stationary part of the discharge will be the same as that for the lower $Z_{\text {eff }}$ case to within a percent or less. If the current ramp-up rate is not increased correspondingly when $Z_{\text {eff }}$ is increased, then the higher values of $Z_{\text {eff }}$ will lead to significantly higher flux consumption at the end of the current ramp. For example, for a fixed current ramp-up time of $160 \mathrm{~s}$, increasing $Z_{\text {eff }}$ from 1.1 to 2.5 will increase the flux swing requirements at the fixed time $t=200 \mathrm{~s}$ from 491 to $522 \mathrm{~Wb}$. This corresponds to an increase in $C_{\mathrm{E}}(200)$ from 0.45 to 0.57 . Thus, to minimize the poloidal flux linkage requirements to get to the stationary phase of the discharge, the plasma current should be ramped up just slow enough that it remains MHD stable, and no slower. In other words, the plasma current ramp-up time must be matched to the plasma conditions to realize the full flux swing potential of the tokamak transformer.

An important result of the present study is that starting the auxiliary heating during the current ramp-up phase does not necessarily reduce the flux swing requirements. If the plasma is heated during the current ramp-up phase, the ramp-up rate must be reduced so that the duration of the ramp-up phase becomes extended. We calculate that adding $10 \mathrm{MW}$ of heating starting when $I_{\mathrm{p}}=17.5 \mathrm{MA}$ will cause the minimum current ramp time to increase from 160 to $200 \mathrm{~s}$, and will delay the start of the stationary phase of the discharge from 195 to $250 \mathrm{~s}$. The amount of flux swing required from the tokamak transformer to get to the start of the stationary phase of the discharge remains unchanged when heating is added.

Another point demonstrated by this paper is that we cannot assume steady state resistive consumption of flux until after $t=t_{\text {crit }}$, the time when the equilibrium is in a resistive stationary state. It is misleading to quote the flux swing requirements at the end of the current ramp, $t=t_{\text {ramp }}$, since the internal inductive measures of the plasma flux are normally still changing at this time.

For the stationary burn phase, we have computed contours of the plasma loop voltage $V_{\mathrm{L}}$ in the POPCON space parametrized by the central density and temperature values $n_{0}$ and $T_{0}$. For the same product of $n_{0} T_{0}$, the temperature dependence of the plasma resistivity $\eta$ will cause $V_{\mathrm{L}}$ to be smaller for higher $T_{0}$. However, the presence of the bootstrap current can modulate these results in that, for the same $T_{0}, V_{\mathrm{L}}$ will be smaller for configurations with a larger product $n_{0} T_{0}$. This result must be factored in with the fusion power curves, the radiation and thermal loss curves, with the thermal stability results, and also with the MHD stability results to define a desirable operating point.

The study presented here could be extended in several ways. One is to allow the plasma current ramp-up rate to be a function of time, rather than being constant as assumed here. We expect this to lead to results qualitatively similar to but quantitatively different from those presented here. The second area that needs improvement is the determination of a proper stability criterion to set the lower limit for $l_{\mathrm{i}}$ during the current ramp-up. These calculations should include both ideal and resistive effects. We also anticipate that this will refine the present study but will not change the conclusions substantially.

Finally, the steady state loop voltage in JSOLVER should be extended to include the effects of sawtooth instabilities. Again, we expect this to modify the results slightly, but not to change the trends and conclusions presented here.

\section{ACKNOWLEDGEMENTS}

The authors would like to thank R. Bulmer, J.C. Wesley and $R$. Sayer for providing the input needed for the calculations presented here, and W. Nevins, D. Post, P. Rutherford and N. Sauthoff for encouragement. This work was supported by the USDOE, under Contract No. DE-AC02-76-CHO3073.

\section{REFERENCES}

[1] REBUT, R.H., et al., in Fusion Technology (Proc. 17th Symp. Rome, 1992), Vol. 1, North-Holland, Amsterdam (1992) 7.

[2] JARDIN, S.C., et al., J. Comput. Phys. 66 (1986) 481.

[3] CHANCE, M.S., et al., in Plasma Physics and Controlled Nuclear Fusion Research 1990 (Proc. 13th Int. Conf. Washington, DC, 1990), Vol. 2, IAEA, Vienna (1991) 87.

[4] JARDIN, S.C., et al., Nucl. Fusion 33 (1993) 371.

[5] ITER TAC-3-05 Physics Report, Physics and Plasma Operation Studies, presented at 3rd Mtg of the ITER Technology Advisory Committee Naka, Japan, 1993;

WESLEY, J.C., MONDINO, P.L., IEEE Trans. Magn. MT-13 (1993).

[6] HAWRYLUK, R.J., et al., Nucl. Fusion 19 (1979) 1519. 
JARDIN et al.

[7] EJIMA, S., et al., Nucl. Fusion 22 (1982) 1313.

[8] CHENG, C.Z., et al., Plasma Phys. Control. Fusion 29 (1987) 351.

[9] VAN HOUTTE, D., et al, in Controlled Fusion and Plasma Physics (Proc. 18th Eur. Conf. Berlin, 1991), Vol. 15C, Part I, European Physical Society, Geneva (1991) 61.
[10] HIRSHMAN, S.P., Phys. Fluids 31 (1988) 3150.

[11] HARRIS, G.R., Comparisons of Different Bootstrap Current Expressions, Rep. EUR-CEA-FC-1436, Association EuratomCEA, Saint-Paul-lez-Durance (1991).

(Manuscript received 22 November 1993) 